\title{
Trophic cascades: linking ungulates to shrub- dependent birds and butterflies
}

\author{
Kristine J. Teichman ${ }^{1 *}$, Scott E. Nielsen ${ }^{2}$ and Jens Roland ${ }^{1}$ \\ ${ }^{1}$ Department of Biological Sciences, Biological Sciences Building, University of Alberta, Edmonton, AB, Canada T6G \\ 2E9; and ${ }^{2}$ Department of Renewable Resources, University of Alberta, 751 General Services Building, Edmonton, AB, \\ Canada T6G $2 \mathrm{H} 1$
}

\begin{abstract}
Summary
1. Studies demonstrating trophic cascades through the loss of top-down regulatory processes in productive and biologically diverse terrestrial ecosystems are limited.

2. Elk Island National Park, Alberta and surrounding protected areas have a wide range of ungulate density due to the functional loss of top predators, management for high ungulate numbers and variable hunting pressure. This provides an ideal setting for studying the effects of hyper-abundant ungulates on vegetation and shrub-dependent bird and butterfly species.

3. To examine the cascading effects of high ungulate density, we quantified vegetation characteristics and abundances of yellow warbler Dendroica petechia and Canadian tiger swallowtail Papilio canadensis under different ungulate density in and around Elk Island National Park.

4. Using Structural Equation Models we found that ungulate density was inversely related to shrub cover, whereas shrub cover was positively related to yellow warbler abundance. In addition, chokecherry Prunus virginiana abundance was inversely related to browse impact but positively related to $P$. canadensis abundance.

5. These results demonstrate a cascade resulting from hyper-abundant ungulates on yellow warblers and Canadian tiger swallowtails through reductions in shrub cover and larval host plant density. The combined effect of the functional loss of top predators and management strategies that maintain high ungulate numbers can decouple top-down regulation of productive temperate ecosystems.
\end{abstract}

Key-words: Dendroica petechia, ecosystem, Papilio canadensis, terrestrial, top-down regulation

\section{Introduction}

Predators are known to regulate populations and communities in a 'top-down' manner across freshwater, marine and terrestrial ecosystems (Estes et al. 2011). Biologically diverse ecosystems are often associated with areas having functional populations of apex predators (Berger et al. 2001; Hebblewhite et al. 2005; Ripple \& Beschta 2006; Sergio et al. 2006). A growing number of studies have shown, however, no association between top predators and biodiversity suggesting that the loss of apex predators does not always alter ecosystem structure (Kerr 1997; Caro et al. 2004; Ozaki et al. 2006; Cabeza, Arponen \& Van Teeffelen 2008). Maintaining biological diversity requires understanding the role of trophic interactions

${ }^{*}$ Correspondence author. E-mail: teichman@ualberta.ca and the potential consequences to biodiversity caused by losing particular linkages.

Trophic cascades occur when changes in the size of one population results in changes in populations at lower levels of the food web (Polis 1999). Numerous factors influence the occurrence and strength of trophic cascades. When resources are highly edible or dominated by only a few species, trophic cascades are more likely to occur (Strong 1992; Polis 1999). Conversely, cascades may be limited by territoriality (Sullivan \& Sullivan 1982), omnivory (Fagan 1997) or self-regulation of guilds through intraguild predation (Polis \& Holt 1992). Food web complexity and species diversity also affect the regulation of populations across trophic levels and thus, the likelihood that a trophic cascade will occur (Pace et al. 1999).

Interaction strength between trophic levels influences ecosystem stability. Many weak interactions may limit the destabilizing effect of strong consumer-resource interac- 
tions (McCann 2000). For simple ecosystems with low diversity, such as the tidal pools examined by Paine (1966), the removal of a top predator (i.e. sea star; Pisaster ochraceus, Brandt) in a 3-tiered food chain resulted in the erosion of species diversity. How a cascade manifests itself can, however, depend on the number of trophic levels in a food chain.

Although the classic trophic cascade is based on a 3-tiered system consisting of predators, herbivores and plants (Paine 1966), top-down forces can manifest themselves through 4 levels in the food chain (Power 1990; Gastreich 1999; Carpenter et al. 2001). Carpenter et al. (2001) illustrated that largemouth bass (Micropterus salmoides, Lacépède), an apex predator, reduced zooplanktivorous fishes leading to an increase in zooplankton and a subsequent decrease in phytoplankton. Top predators can therefore indirectly reduce the abundance and production of primary producers or, more commonly, reduce herbivory, thus increasing primary production (Estes et al. 2011).

Trophic cascades have been frequently observed in aquatic systems (Carpenter \& Kitchell 1988; Strong 1992; Estes \& Duggins 1995; Polis 1999). Most trophic cascades in terrestrial ecosystems have been reported from small scale experiments involving invertebrate predators such as spiders, beetles and ants (Pace et al. 1999; Schmitz, Hamback \& Beckerman 2000; Persson 2005). Empirical studies of large mammalian cascades are fewer partly due to the logistical constraint in experimentally manipulating large carnivore populations (Ripple \& Beschta 2006). Those terrestrial studies that have examined the reduction or loss of large apex predators have frequently shown an increase in herbivory resulting in subsequent changes in ecosystem structure and stability (McLaren \& Peterson 1994; Ripple et al. 2001; Terborgh et al. 2001; Sergio et al. 2008). Two forms (mechanisms) of trophic cascades may occur: density-dependent or trait-mediated cascades (Terborgh et al. 2001). Density-dependent cascades occur when plant biomass increases indirectly by reducing herbivorous prey populations, while trait-mediated cascades occur when herbivore behaviour is altered resulting in local increases in plant biomass (Terborgh et al. 2001).

A density-dependent cascade occurred in riparian areas of Zion National Park when reductions in cougars (Puma concolor Linnaeus) indirectly limited cottonwood (Populus fremontii, Watson) recruitment due to increased deer (Odocoileus hemionus, Rafinesque) herbivory along riparian edges (Ripple \& Beschta 2006). Loss of cottonwood trees resulted in fewer flowering plants, amphibians, lizards and butterflies. In some cases, it is difficult to discern the mechanism of a trophic cascade (Trussell, Ewanchuk \& Bertness 2002; Kauffman, Brodie \& Jules 2010). A behaviourally mediated mechanism was demonstrated in Yellowstone National Park following the reintroduction of wolves (Canis lupus, Linnaeus) where aspen (Populus tremuloides, Michaux) recruitment increased due to decreases in elk densities and/or behavioural changes in elk (Cervus elaphus, Linnaeus) due to a 'landscape of fear' response (Ripple \& Larsen 2000; Fortin et al. 2005; Ripple $\&$ Beschta 2012). More recent work in the same system showed, however, no differences in P. tremuloides recruitment in areas with low vs. high predation risk, which suggests a lack of a behaviourally mediated trophic cascade (Kauffman, Brodie \& Jules 2010).

The objective of this study was to test a density-dependent, trophic cascade for a resilient forested ecosystem in eastcentral Alberta that is characterized as having dominant woody species with vegetative resprouting capabilities that facilitate rapid recovery from disturbance (Bork, Hudson \& Bailey 1997; White, Olmsted \& Kay 1998). We evaluate the direct impacts of ungulate density on vegetation and the indirect effects of ungulate density on shrub-dependent bird and butterfly species within an outside of Elk Island National Park, a protected area surrounded by an ungulate-proof fence and some of the highest ungulate densities in Canada (Blyth \& Hudson 1987; Hood \& Bayley 2008). Due to logistical constraints of quantifying entire bird and butterfly communities, we tested for species-level trophic cascades for two relatively common and easily identifiable species: yellow warblers (Dendroica petechia, Linnaeus) and Canadian tiger swallowtails (Papilio canadensis, Rothschild \& Jordan). Moderate browsing pressure may benefit shrub-nesting birds by creating nest sites (Holt, Fuller \& Doman 2011; Erin Bayne, pers. comm.) or butterfly larval performance (including P. canadensis [Scriber 1991]) through increasing plant carbon and nitrogen content. However, due to hyper-abundant ungulate densities, we predicted that, despite having evolved an ability to recover rapidly from disturbance, high ungulate density and/or browse impact (BI) in this system should result in structural and compositional changes in vegetation that limit nest sites for D. petechia and larval host plants for $P$. canadensis thus reducing their abundance.

\section{Materials and methods}

\section{STUDY AREA}

The study was conducted in the Beaver Hills ecosystem located $\sim 45 \mathrm{~km}$ east of Edmonton, Alberta, Canada. The area includes protected areas (Fig. 1) that represent a broad gradient in ungulate density and thus browsing pressure (Fig. 2).

Elk Island National Park is a $196 \mathrm{~km}^{2}$ reserve that was fenced immediately after its establishment in 1906. North and South Elk Island National Park are separated by fence and a major highway. Ungulates occur at high densities in the park due to the ungulate-proof fence, the lack of resident apex predators including wolves, cougars or grizzly bears (C. lupus, P. concolor, Ursus arctos, Linnaeus), hunting and active management of ungulate habitat. Park management includes both ungulate culling and a bison relocation programme when densities exceed a management carrying capacity. Coyotes (Canis latrans, Say) and red foxes (Vulpes vulpes, Linnaeus) are common to the park, while black bears (Ursus americanus, Pallas) are absent. Ungulate species include elk (Cervus canadensis, Erxleben), moose (Alces alces, 


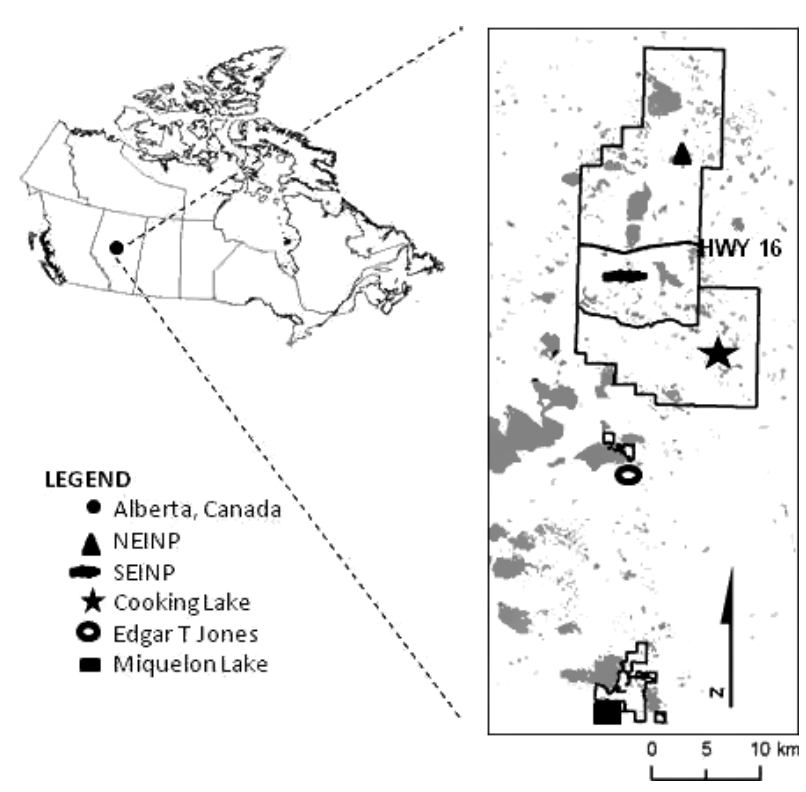

Fig. 1. Location of study area in the Beaver Hills region of Alberta, Canada including Elk Island National Park, Cooking Lake-Blackfoot Provincial Recreation Area, Edgar T. Jones Natural Area and Miquelon Lake Provincial Park. Elk Island is divided by a major highway into north and south sections. Gray represents the lakes and other water bodies.

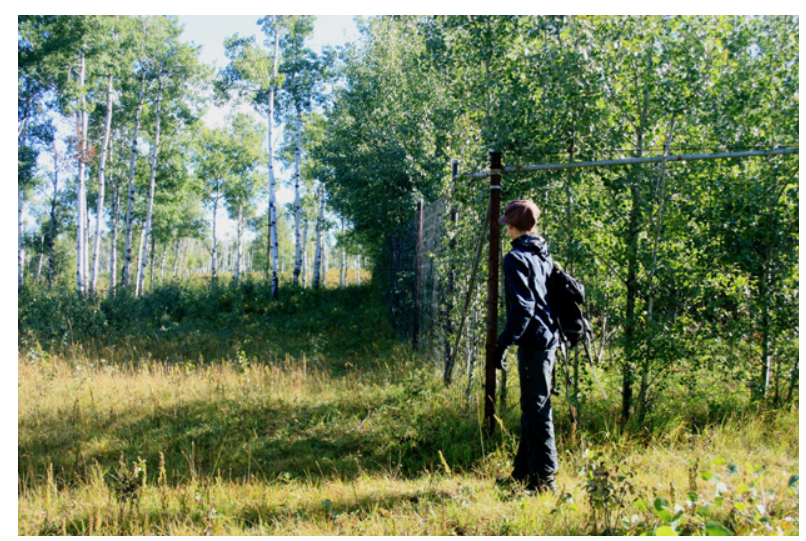

Fig. 2. Photos from the south part of Elk Island National Park illustrating change in shrub structure and composition after 13 years (since 1999) of ungulate exclusion (on the right).

Linnaeus), plains bison (Bison bison bison, Linnaeus), wood bison (Bison bison, Linnaeus), white-tailed deer (Odocoileus virginianus, Zimmermann) and mule deer (Odocoileus hemionus). All other reserves in the Beaver Hills contain these same ungulate species with the exception of bison that occur only in Elk Island National Park. Apex predators outside of the park include $P$. concolor at low densities and rare sightings of $C$. lupus. Similar to inside Elk Island National Park, C. latrans and V. vulpes are common outside of Elk Island park boundaries, with occasional reports of $U$. americanus.

Elk Island National Park actively manages ungulate habitat through prescribed burning. To avoid confounding effects associated with differences in number of burns, intensity of burns and time since burned, areas of prescribed burns were not included in this analysis. Of the provincial parks outside of Elk Island
National Park, Cooking Lake-Blackfoot Provincial Recreation Area $\left(98.8 \mathrm{~km}^{2}\right)$ is the only area in the study that supports seasonal ungulate hunting and is used in some areas for seasonal livestock grazing. To support seasonal grazing, parts of the upland deciduous forests were logged in the 1950s. In 1987, a fence was built to limit grazing to a $28.75 \mathrm{~km}^{2}$ area of pastures that was seeded with agricultural species. These areas were not used in this study. Miquelon Lake Provincial Park $\left(\sim 13 \mathrm{~km}^{2}\right)$ and Edgar T Jones Natural Area $\left(0.92 \mathrm{~km}^{2}\right)$ are designated protected areas with no apparent ungulate management. Although these last two parks are considerably smaller than Elk Island National Park and Cooking Lake, the surrounding matrix of habitat is similar so reserve size should have no major effect.

All study sites were characterized as having a mosaic of wetlands surrounded by P. tremuloides and balsam poplar (Populus balsamifera, Linnaeus) forests with sporadic patches of black and white spruce (Picea mariana, Miller and P. glauca, Moench, respectively). Shrub understorey is dominated by beaked hazelnut (Corylus cornuta, Marshall) and other shrub species including saskatoon (Amelanchier alnifolia, Nuttall), chokecherry (Prunus virginiana, Linnaeus), willow (Salix spp., Linnaeus), rose (Rosa spp., Linnaeus) pin cherry (Prunus pensylvanica, Linnaeus filius), red raspberry (Rubus idaeus, Linnaeus), bush cranberry (Viburnum spp., Linnaeus), red-osier dogwood (Cornus stolonifera, Linnaeus), western snowberry (Symphoricarpos occidentalis, Hook), currant (Ribes spp., Linnaeus), honeysuckle (Lonicera spp., Linnaeus) and buffaloberry (Shepherdia canadensis, Linnaeus \& Nutt).

\section{SITE SELECTION}

Shrub and forest communities with riparian-like characteristics were identified from an Alberta land cover classification (Canadian Forest Service 2007). Land cover was reclassified as forest edges and watercourses (Natural Resources Canada 2002) to define locations of riparian edges. Riparian edges $\geq 300 \mathrm{~m}$ in length were identified in a GIS and 59 random locations (points) at least $300 \mathrm{~m}$ apart were selected for sampling.

\section{ABUNDANCE OF PAPILIO CANADENSIS}

We estimated the abundance of $P$. canadensis using Pollard Walk surveys (Pollard \& Yates 1993; Royer, Austen \& Newton 1998). Pollard transects were $300 \mathrm{~m}$ long and ran parallel to wetlands along the shrub-grass interface formed at the edge of wetlands (Fig. 3). Pollard Walks were conducted between June 1 and July 1 of 2011 during peak flight times and suitable temperature and wind conditions (Pollard \& Yates 1993) with the observer recording P. canadensis seen within $5 \mathrm{~m}$ of the transect in front of and above the observer.

\section{ABUNDANCE OF DENDROICA PETECHIA}

In May and June of 2011, abundance of D. petechia was estimated at each of the 59 sample sites using call playbacks. Call playbacks were located at the centre of each $300 \mathrm{~m}$ transect and within the middle of the shrub community (i.e. the ecotone between the forest and open wetland communities, Fig. 3). Call playbacks were conducted by playing a $1 \mathrm{~min}$ call followed by $1 \mathrm{~min}$ of silence during which time the observer recorded any D. petechia visible or audible. Call playbacks 
Fig. 3. Ungulate pellets, vegetation characteristics, and relative abundance of yellow warbler and Canadian tiger swallowtail were quantified at 59 sites. Pellet transects were perpendicular to the wetland thus crossing grass, shrub and forest zones. Vegetation surveys were conducted in the shrub and forest areas with a maximum of 6 surveys per site. Yellow warbler playbacks were performed in the middle of the shrub zone while butterfly transects occurred parallel to the wetland along the grass-shrub interface.

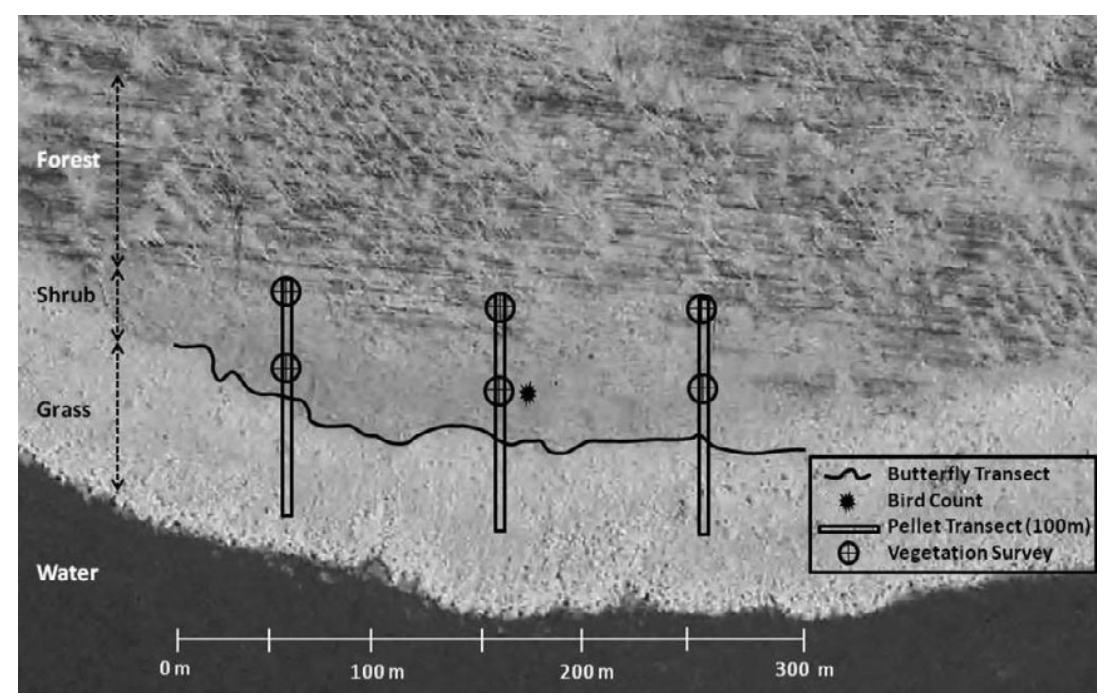

occurred between half an hour before sun-rise and 10 am provided that weather conditions were favourable (i.e. no precipitation and $<2$ on the Beaufort Wind Scale; Alberta Biodiversity Monitoring Institute 2007). All counts were made by two observers; both observers recording playback observations at 30 sites prior to independent observations. To eliminate double counting of $D$. petechia, any bird believed to be previously detected was not recorded.

\section{UNGULATE DENSITY}

We used pellet group surveys along $100 \mathrm{~m}$ long by $2 \mathrm{~m}$ wide belt transects to index ungulate density (Fig. 3). Pellet transects were initially surveyed in the fall (September-October) of 2011 and marked with aluminium stakes for revisits in the spring. All ungulate faecal pellets within $1 \mathrm{~m}$ of transects were removed in the fall survey. In May 2011, pellet transects were revisited in order to estimate winter ungulate density based on accumulated pellet group counts from fall removal date.

Pellet count transects were perpendicular to $300 \mathrm{~m}$ long butterfly transects running from the grassy wetland into the forest (Fig. 3). Three pellet count transects $100 \mathrm{~m}$ apart were surveyed for each site for a total search area of $600 \mathrm{~m}^{2}$ or 0.06 ha. Pellets were distinguished by species and classified as large ( $>5$ pellets) or small ( $\leq 5$ pellets) groups (Hood \& Bayley 2008). We noted the vegetation class where pellets were found (grass, shrub or forest) and pooled pellets across vegetation types to obtain a per site sampling unit. Only large pellet groups were used to prevent overestimation of animals defecating on the move. We converted pellet density to ungulate density for each species using the formula:

Density $=\frac{X}{A \times F \times t}$,

where $X$ is the number of pellet groups, $A$ is the area of the plot, $F$ is the defecation rate and $t$ is the time of pellets to accumulate at a site (Skalski, Ryding \& Millspaugh 2005). Defecation rates vary due to diet, season, location, recording methodology and whether animals were free ranging or penned (see Appendix S1). Because species-specific defecation rates were unknown for this study system, we used the average defecation rates for each species (moose, deer, elk and bison) based on estimates from the published literature (see Appendix S1). Averages used included 15.9 pellet groups per day for moose, 18.3 pellet groups per day for deer, 14 pellet groups per day for elk and 9 plops per day for bison (see Appendix S1).

Increased browsing reduces availability of herbaceous forage due to snow accumulation and energetic costs associated with foraging in snow (Parker, Robbins \& Hanley 1984; Fancy \& White 1985). All ungulate species, including bison, are known to browse (Holsworth 1960; Painter \& Ripple 2012), particularly during the winter months. Therefore, once ungulate density was estimated for each species, we summed densities across all ungulate species to estimate total ungulate density for each site. We also compared ungulate density among North Elk Island National Park (NEINP), South Elk Island National Park (SEINP) and outside Elk Island National Park (OEINP). North and South Elk Island National Park are fenced areas that were expected to have higher ungulate density than areas outside of Elk Island National Park.

\section{VEGETATION SURVEYS}

In 2010 and 2011, vegetation surveys were conducted along each of the three pellet transects per sampling site. Plots were located in the middle of the shrub zone and at a $15 \mathrm{~m}$ distance into the forest, for a maximum of three shrub plots and three forest plots per site (Fig. 3). Shrubs were considered to be any species with a $\mathrm{DBH}<5 \mathrm{~cm}$. Because all statistical modelling was performed at the scale of a site (i.e. maximum 6 plots per site), shrub measures at the plot level were averaged to estimate a single site sampling unit.

\section{Shrub density}

We used a variation of the point-centred quarter method to estimate shrub density (Y. Feng, University of Alberta, unpublished). We restricted plot radius to $3 \mathrm{~m}$ because it was impractical to do a limitless search for each species. As a result, some plots had fewer than 4 observed distances for each of the focal shrub species. We accounted for quadrants where a species was absent by using the equation: 
$\hat{\lambda}_{q}=\frac{\pi}{4}\left(\frac{a_{q 1}^{2}+. .+a_{q k}^{2}+(4-k) r^{2}}{k}\right)$,

where $a$ is the distance from the centre point to the closest individual shrub, $k$ is the number of quadrants with a plant and $r$ is the search radius $(3 \mathrm{~m})$. This equation calculates an area per plant, from which we estimate plants per unit area. The closest stem to the centre point was used to estimate shrub density, particularly focusing on densities for target plants of Salix spp., $P$. tremuloides and $P$. virginiana.

\section{Ungulate browse}

We estimated ungulate browse of P. virginiana, Salix spp. and $P$. tremuloides using browse severity and percentage browse indices similar to Hood \& Bayley (2009). Prunus virginiana, Salix spp. and $P$. tremuloides were examined because these species are known to be host plants for P. canadensis caterpillars. Browse levels were assessed for the closest stems to the centre point of a plot for each selected shrub species. Percentage browse was estimated as the ratio of the number of browsed branches to total number of branches from the main stem and recorded as 1 of 5 ordinal browse categories representing, $0 \%(0), 1-5 \%(1), 6-20 \%$ (2), $20-50 \%$ (3) and $51-100 \%$ (4). Browse severity, on the other hand, was estimated using qualitative visual assessments of individual shrubs based on the amount of leader and secondary growth, hedging and amount of dead wood. Browse severity was categorized into none (0), low (1), medium (2) and high (3) classes. For example, a browsed branch with no dead wood and some healthy leader growth was considered 'low' browse severity, while a branch with substantial secondary growth (hedging) and excessive deadwood was classified as 'high' browse severity. When there were differences of browse severity on the branches of an individual, the median value was recorded. For example, if 6 stems were browsed and the browse severity equated to 1, 2, 2, 2, 3, 3 then a median (2) browse severity was recorded.

A BI Index was estimated as the multiplicative of the percentage browse and browse severity (Hood \& Bayley 2009). That is, if a shrub had $80 \%$ browse (4) with a 'medium' browse severity (2) then the BI index would be 8 . This index was used to quantify the impact of browsing on selected butterfly larval host shrubs.

\section{Horizontal cover}

Horizontal shrub cover was estimated for each plot using a modified Robel pole (Robel et al. 1970) or checkerboard at $0.5 \mathrm{~m}$ increment heights up to $2 \mathrm{~m}$. Standing at a $5 \mathrm{~m}$ distance from the checkerboard, the observer recorded horizontal cover in the four cardinal directions with average cover at each height class. We averaged horizontal cover across plots and height classes to estimate site-level horizontal cover at $0.5,1,1.5$ and $2 \mathrm{~m}$ heights. To estimate total site-level horizontal cover (i.e. all height classes combined), the percentage cover of all height classes were averaged.

\section{Tree canopy cover}

To estimate tree canopy cover for each site, a single observer used a spherical densiometer (Lemmon 1956) with obstructed shrubs moved to the side of the observer to observe tree canopy cover. Canopy cover was averaged across plots for a site-level estimate of canopy cover.

\section{GRASSLAND, SHRUB AND FOREST ZONES}

At each site, the width of each vegetation zone was measured in each pellet transect. Grassland habitats were characterized by having $<50 \%$ emergent vegetation closest to the water and $<50 \%$ shrub in the uplands at the grass-shrub interface. Shrub habitat was identified as having $\geq 50 \%$ shrub cover and less than five trees within a $5 \mathrm{~m}$ radius $\left(78.5 \mathrm{~m}^{2}\right.$ plot). All species were considered trees if their DBH (diameter at breast height) was $\geq 5 \mathrm{~cm}$. Forests were defined as areas having $\geq 5$ trees within a $5 \mathrm{~m}$ radius equating to a stem density of 636 or more trees per hectare. A $5 \mathrm{~m}$ radius was used because broad vegetation patterns (i.e. grassland, shrub, and forest zones along water bodies) reflected discrete edges rather than gradual transitions to designated vegetation types. Total width of each vegetation layer was then used to estimate proportion grassland, shrub and forest for each site.

\section{STATISTICAL APPROACH}

We used structural equation models (SEMs) in STATA/SE-64 to examine direct and indirect relationships between ungulates, shrubs, butterflies and birds. Prior to analysis, bivariate relationships were examined between dependent and independent variables using generalized linear models (GLMs) in order to identify potential nonlinear relationships by adding quadratic terms (Grace 2006). Akaike Information Criteria (AIC) was used to assess support of either a linear or nonlinear effect. If the difference in AIC values was $<2$, we used the simpler linear model.

Dependent variables that were non-normally distributed were log-transformed with a constant (value of 1) to approximate a normal distribution. Structure of variables and relationships in the SEMs was based on theoretical causal relationships between variables and then altered according to the modification indices to improve model fit. We tested combinations of vegetation and ungulate variables without altering the overall structure of the model and used variables that resulted in the best overall model fit. Modifications were only considered if they were ecologically relevant. A $\chi^{2}$ test was used to determine the overall model fit because a nonsignificant result $(P>0.05)$ is a good indication of whether the data and model fit are adequate (Grace 2006). Standardized path coefficients and $P$-values were used to assess significance of individual variables within the model. Due to small sample sizes and the exploratory nature of the analyses, coefficients with $P<0 \cdot 1$ were considered significant.

\section{Hypothesized cascades to Dendroica petechia}

We hypothesized that D. petechia would have a direct path from ungulate density to horizontal shrub cover. In this case, ungulate density was used as a surrogate for browsing intensity where it would be expected that increases in ungulate density would result in reduced horizontal shrub cover (Baker, Peinetti \& Coughenour 2005). We hypothesized that amount of shrub habitat would be reduced by ungulate density because overgrazing along the grassshrub interface may limit shrub seedling recruitment and establishment of young shrubs, thereby limiting the extent of the shrub 
zone (Dublin, Sinclair \& McGlade 1990; Côté et al. 2004). Furthermore, overbrowsing of shrubs by moose and deer may limit shrub habitat by reducing shrub density (Prins \& Van der Jeugd 1993). Bi-directional relationships between horizontal shrub cover and ungulate density and shrub habitat and ungulate density were not used because the SEM cannot correlate endogenous and exogenous variables (program STATA/SE-64). Direct paths from both horizontal shrub cover and shrub habitat to $D$. petechia abundance were selected because $D$. petechia prefer thick shrub understorey in areas with more shrub habitat in order to reduce risk from predation and brood parasites (Knopf \& Sedgewick 1992). A direct path from canopy cover to $D$. petechia abundance was also selected because $D$. petechia prefer open or nonforested shrub habitat (Hanski, Fenske \& Niemi1996). We also included direct paths from horizontal shrub cover and amount of shrub habitat to canopy cover since canopy cover limits precipitation and light to the shrub layer (Anderson, Loucks \& Swain 1969), thereby limiting plant growth.

\section{Hypothesized cascade to Papilio canadensis}

We hypothesized that $P$. canadensis would have direct paths from ungulate density and $\mathrm{BI}$ on $P$. virginiana, $P$. tremuloides and Salix spp. shrub densities. We expected that increased ungulate density and browsing pressure would limit shrub density (Bailey, Irving \& Fitzgerald1990; Singer \& Renkin 1995). The effects of herbivory on shrubs can enhance plant quality, thereby increasing butterfly performance (Scriber 1991) or, alternatively, limit foliage for butterfly larva thus limiting larval development (Ouellet, Boutin \& Heard 1994). Because we expected browsing pressure on $P$. canadensis larval host plants to be high, we hypothesized that density of $P$. virginiana, $P$. tremuloides and Salix spp. (Layberry, Hall \& Lafontaine1998) would be positively related to $P$. canadensis abundance. We hypothesized a positive direct relationship between $P$. canadensis abundance and amount of shrub habitat because more shrub habitat should increase larval host plant density. A path from grassland habitat to $P$. canadensis abundance was included because avian predation rates of adult butterflies are expected to be higher in open grassland than areas with shrub and forest cover. Although a general response of flying butterflies to predation is to erratically shift flight patterns to unpredictable changes in direction (Marden \& Chai 1991), we expected butterflies to have greater success of escaping avian insectivores in areas with more shrub or forest. We hypothesized that ungulate density and BI of P. canadensis' larval host plants would be co-related, so bidirectional paths were used between ungulate density and BI. Similarly, we expected grassland and shrub habitats to influence, as well as be influenced, by ungulate density. A bi-directional path was therefore used between ungulate density and grassland/ shrub habitats.

\section{Results}

\section{PATTERNS OF UNGULATE DENSITY}

Ungulate density varied substantially among sampling sites with bison and elk having higher densities than moose and deer (Fig. 4a). Total ungulate density among sites ranged from 2.3 to 53.4 ungulates $\mathrm{km}^{-2}$ with an average of 19.2 ungulates $\mathrm{km}^{-2}$. Overall, SEINP had the highest ungulate density, being significantly higher than NEINP $\quad(\beta=0.64, \quad P<0.01) \quad$ or OEINP $\quad(\beta=0.90$, $P<0.01$; Fig. 4b). Ungulate density in NEINP was significantly higher than outside the Park $(\beta=0 \cdot 26$, $P=0.07$; Fig. 4 b). Bison density was positively related to amount of grassland habitat $(\beta=4.48, P<0.01)$, while moose were positively related to amount of shrub habitat $(\beta=1.02, \mathrm{SE}=0.52, P=0.05)$. Deer showed no preference for amount of grassland $(\beta=0.04, \mathrm{SE}=0.61$, $P=0.95)$, shrub $(\beta=-0.77, \mathrm{SE}=0.67, P=0.79)$ or forest $(\beta=0.78, \mathrm{SE}=0.45, P=0.86)$, while elk were positively related to amount of forest $(\beta=0.68, \mathrm{SE}=0 \cdot 36$, $P=0 \cdot 06)$.

\section{DENDROICA PETECHIA CASCADE}

No modifications were needed to improve model fit $\left(\chi_{2}^{2}=1.79, P=0.41\right)$ of the hypothesized yellow warbler model and thus accepted as is (Table 1; Fig. 5a). Variance explained in the model was excellent $\left(r^{2}=0 \cdot 52\right)$. Ungulate density was found to be inversely related to horizontal cover $(\beta=-0.29, P=0.01)$ with a positive relationship between horizontal cover and abundance of $D$. petechia $(\beta=0.20, P=0.09$; Table 2$)$. There was also a positive, direct relationship between proportion shrub habitat and abundance of $D$. petechia $(\beta=0.34, P=0.02)$, an inverse relationship between canopy cover and amount of shrub
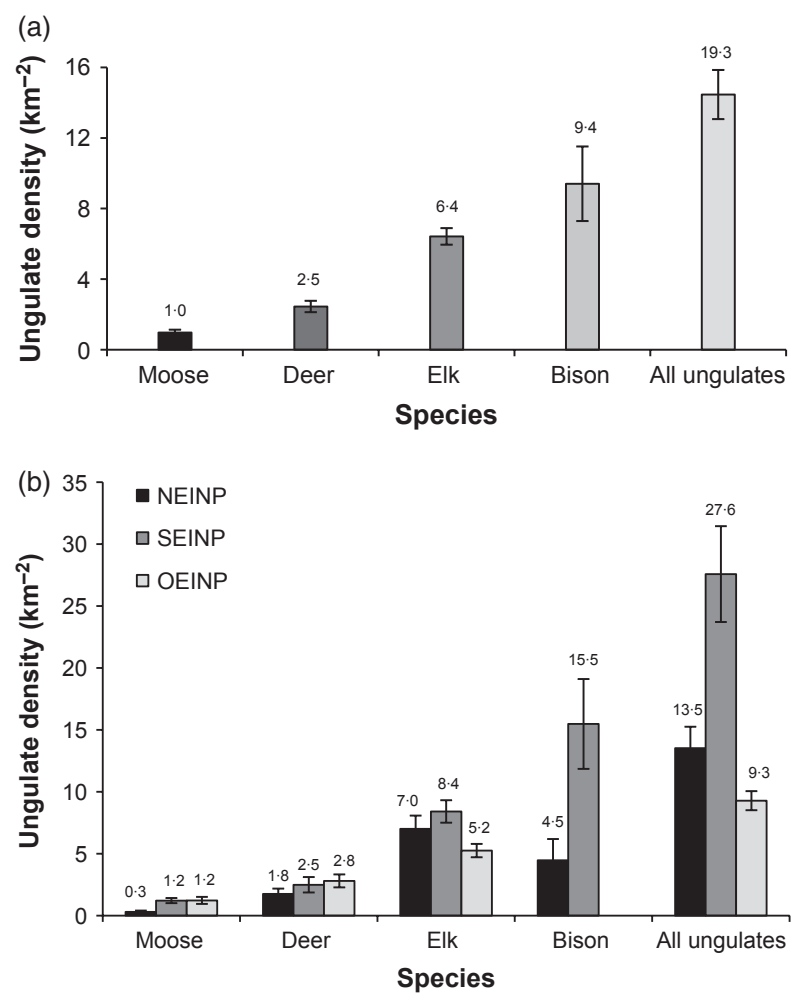

Fig. 4. Average ungulate density for (a) study area and (b) by study sites for north Elk Island National Park (NEINP), south Elk Island National Park (SEINP) and outside Elk Island National Park (OEINP). 
Table 1. Expected and observed outcomes of the yellow warbler (YW) and canadian tiger swallowtail (CTS) structural equation model (SEM) including coefficients for direct, indirect and total effect for hypothesized causal relationships

\begin{tabular}{|c|c|c|c|c|}
\hline \multirow[b]{2}{*}{ Expected outcomes } & & \multicolumn{3}{|c|}{ Observed outcomes } \\
\hline & & Direct paths & Indirect paths & Total effects \\
\hline \multicolumn{5}{|l|}{ Yellow warbler SEM } \\
\hline \multirow[t]{3}{*}{ Increase ungulate density } & Decrease horizontal cover & $-0 \cdot 294 * *$ & None & -0.294 \\
\hline & Decrease shrub habitat & $-0.040 \dagger$ & None & $-0 \cdot 040$ \\
\hline & Reduce YW & None & $-0.072 \dagger$ & -0.072 \\
\hline Reduce horizontal cover & Decrease YW & $0 \cdot 196^{*}$ & None & $0 \cdot 196$ \\
\hline \multirow[t]{3}{*}{ Increase canopy cover } & Reduce horizontal cover & $0 \cdot 269 * * \dagger$ & None & $0 \cdot 269$ \\
\hline & Reduce shrub habitat & $-0 \cdot 630^{* *}$ & None & -0.630 \\
\hline & Reduce YW & $-0 \cdot 279 * *$ & $-0 \cdot 163$ & $-0 \cdot 442$ \\
\hline Increase shrub habitat & Increase YW & $0.342 * *$ & None & $0 \cdot 342$ \\
\hline \multicolumn{5}{|l|}{ Canadian tiger swallowtail SEM } \\
\hline \multirow[t]{2}{*}{ Increase chokecherry browse } & Decrease chokecherry & $-0.792 * *$ & None & -0.792 \\
\hline & Reduce CTS & None & $-0 \cdot 207$ & -0.207 \\
\hline \multirow[t]{2}{*}{ Increase willow browse } & Decrease willow & $-0 \cdot 186 \dagger$ & None & $-0 \cdot 186$ \\
\hline & Reduce CTS & None & -0.036 & -0.036 \\
\hline \multirow[t]{2}{*}{ Increase aspen browse } & Decrease aspen & $-0.123 \dagger$ & None & $-0 \cdot 123$ \\
\hline & Reduce CTS & None & 0.008 & 0.008 \\
\hline \multirow[t]{3}{*}{ Increase ungulate density } & Decrease chokecherry & $0 \cdot 100 \dagger$ & None & $0 \cdot 100$ \\
\hline & Decrease willow & $0 \cdot 171 \dagger$ & None & $0 \cdot 171$ \\
\hline & Decrease aspen & $0.255 \dagger$ & None & $0 \cdot 255$ \\
\hline Increase shrub habitat & Increase CTS & $0.084 \dagger$ & None & 0.084 \\
\hline Increase grass habitat & Reduce CTS & $0.214 \dagger$ & None & $0 \cdot 214$ \\
\hline Reduce willow density & Decrease CTS & $0 \cdot 194^{\dagger}$ & None & $0 \cdot 194$ \\
\hline Reduce chokecherry & Decrease CTS & $0 \cdot 262^{*}$ & None & $0 \cdot 262$ \\
\hline Reduce aspen & Decrease CTS & $-0.061 \dagger$ & None & -0.061 \\
\hline
\end{tabular}

$* P<0 \cdot 1, * * P<0.05$.

$\dagger$ Represents paths where the expected outcome is different from the observed outcome.

habitat $(\beta=-0.63, P<0.01)$, and an inverse relationship between canopy cover and D. petechia $(\beta=-0 \cdot 28$, $P=0 \cdot 05)$. Not all hypothesized relationships were supported (Table 2). There was a positive direct effect of canopy cover on horizontal cover $(\beta=0 \cdot 27, P=0.02)$ and no significant effect between amount of shrub habitat and ungulate density $(\beta=-0 \cdot 04, P=0 \cdot 63)$.

\section{PAPILIO CANADENSIS CASCADE}

No modifications were needed for the hypothesized $P$. canadensis model $\left(\chi_{19}^{2}=14.39, P=0.76\right)$ and therefore accepted as is (Table 3; Fig. 5b). Variance explained in the model was excellent $\left(r^{2}=0.64\right)$. Of the larval host plants examined, only $P$. virginiana density was related to system factors with $P$. virginiana density inversely related to $\mathrm{BI}(\beta=-0.79, \quad P<0.01$; Table 3$)$. As $P$. virginiana density increased, so too did abundance of $P$. canadensis $(\beta=0.26, P=0.09)$. An indirect negative effect of $P$. virginiana browse on abundance of $P$. canadensis was also supported $(\beta=-0 \cdot 21, P=0 \cdot 10)$. Ungulate density was positively related to browse in both $P$. virginiana $(\beta=0.53, \quad P<0.01)$ and $P$. tremuloides $\quad(\beta=0.71$, $P<0.01)$. Grassland habitat was positively related to ungulate density $(\beta=0.05, P<0 \cdot 01)$. All other hypothesized relationships (as described in the methods section) were insignificant (Table 3 ).

\section{Discussion}

High ungulate density had a significant effect on vegetation structure and composition, reducing understorey cover and shrub density, particularly $P$. virginiana. Indirect negative effects of high ungulate numbers on shrubdependent birds and butterflies were consistent with other studies testing the impact of hyper-abundant ungulates on other trophic levels (Berger et al. 2001; Ripple \& Beschta 2006). Many studies that evaluate the consequences of either the loss or reintroduction of top predators focus on direct negative effects on herbivore prey and indirect effects on plant communities (McLaren \& Peterson 1994; Ripple et al. 2001; Fortin et al. 2005). However, because of the complexities of species interactions across trophic levels, the loss of top-down regulatory processes can alter ecosystem structure and function through multiple pathways, which may not include a consumer-resource link (Hebblewhite et al. 2005; Ripple \& Beschta 2006). We demonstrate a nonconsumer-resource relationship between ungulate density, horizontal shrub cover and D. petechia abundance.

\section{THE DENDROICA PETECHIA CASCADE}

This study illustrates a cascading effect in areas with high ungulate density on $D$. petechia by an ungulate-induced 
Fig. 5. Structural Equation Model for (a) yellow warbler (Dendroica petechia) and (b) Canadian tiger swallowtail (Papilio canadensis). Thickness of the solid (direct effect) line represents the strength of the standardized path coefficients. A dotted line represents non-significant results. $*=P<0.1, * *=P<0.05$.
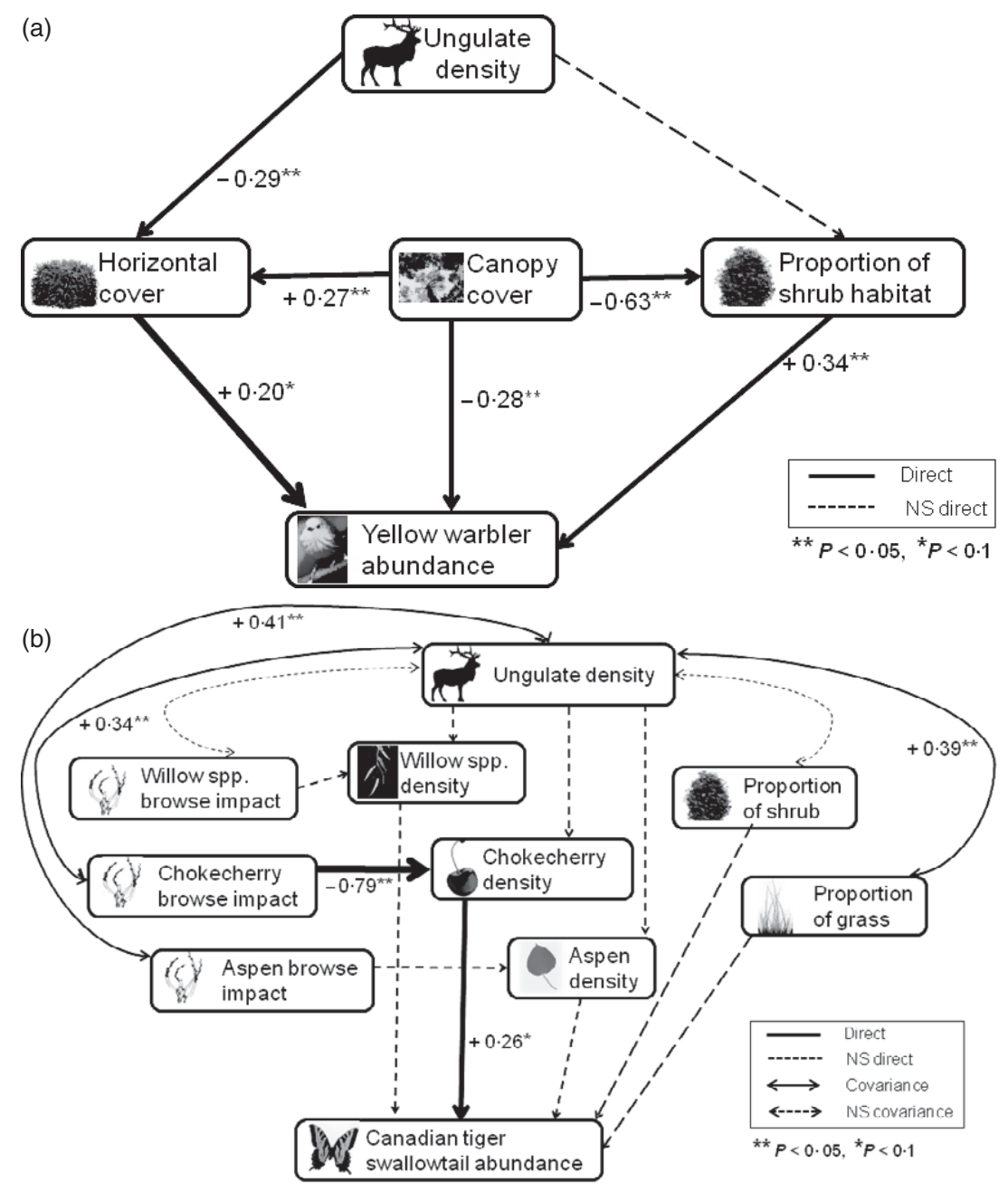

Table 2. Yellow warbler structural equation model unstandardized and standardized direct path coefficients, standard error (SE) of the unstandardized coefficients and $z$ test results. Paths are represented from the dependent variables (lower case) to the independent variable (italicized)

\begin{tabular}{|c|c|c|c|c|c|}
\hline Variables & Coefficients & SE & $z$-value & $P$-value & Standardized Coefficients \\
\hline \multicolumn{6}{|l|}{ Shrub habitat } \\
\hline ungulate density & $-0 \cdot 010$ & 0.025 & $-0 \cdot 39$ & $0 \cdot 70$ & $-0 \cdot 040$ \\
\hline canopy cover & $-0 \cdot 005$ & $0 \cdot 001$ & $-6 \cdot 11$ & $<0.01$ & -0.630 \\
\hline \multicolumn{6}{|l|}{ Horizontal cover } \\
\hline ungulate density & $-0 \cdot 068$ & 0.028 & $-2 \cdot 47$ & $0 \cdot 01$ & $-0 \cdot 294$ \\
\hline canopy cover & $0 \cdot 002$ & $0 \cdot 001$ & $2 \cdot 25$ & 0.02 & $0 \cdot 269$ \\
\hline \multicolumn{6}{|l|}{ Yellow warblers } \\
\hline horizontal cover & 0.786 & 0.463 & 1.70 & 0.09 & $0 \cdot 196$ \\
\hline canopy cover & -0.009 & 0.004 & -1.93 & 0.05 & $-0 \cdot 279$ \\
\hline shrub habitat & 1.322 & 0.542 & $2 \cdot 44$ & 0.02 & $0 \cdot 342$ \\
\hline
\end{tabular}

reduction in horizontal shrub cover. Ungulate density was inversely related to horizontal cover with shrub cover positively related to $D$. petechia abundance.

High ungulate density can negatively impact neotropical bird density, including $D$. petechia, where vegetation structure is altered by browsing (Berger et al. 2001; Olechnowski \& Debinski 2008). In general, dense understorey is considered favourable for $D$. petechia by reducing detect- ability of nest sites by predators and brood parasites (Knopf \& Sedgewick 1992; Thompson 2007) thereby increasing bird productivity. On the other hand, moderate ungulate density may facilitate nesting opportunities for D. petechia because short branches with overhead leaf cover create more suitable nest sites (Holt, Fuller \& Doman 2011; Erin Bayne, pers. comm.). However, D. petechia select nest sites based on vegetation patterns 
Table 3. Canadian tiger swallowtail structural equation model unstandardized and standardized direct path coefficients, the standard error (SE) of the unstandardized coefficients and $z$ test results. Paths are represented from the dependent variable (lower case) to the independent variable (italicized)

\begin{tabular}{|c|c|c|c|c|c|}
\hline Variable & Coefficient & SE & $z$-value & $P$-value & Standardized Coefficient \\
\hline \multicolumn{6}{|l|}{ Chokecherry density } \\
\hline chokecherry browse & -0.064 & $0 \cdot 009$ & $-7 \cdot 18$ & $<0 \cdot 01$ & -0.792 \\
\hline ungulate density & 0.028 & $0 \cdot 031$ & 0.92 & $0 \cdot 36$ & $0 \cdot 101$ \\
\hline \multicolumn{6}{|l|}{ Willow density } \\
\hline willow browse & -0.012 & $0 \cdot 011$ & $-1 \cdot 20$ & $0 \cdot 23$ & $-0 \cdot 186$ \\
\hline ungulate density & 0.047 & $0 \cdot 043$ & $1 \cdot 10$ & $0 \cdot 27$ & 0.171 \\
\hline \multicolumn{6}{|l|}{ Aspen density } \\
\hline aspen browse & -0.017 & $0 \cdot 023$ & -0.72 & $0 \cdot 47$ & $-0 \cdot 123$ \\
\hline ungulate density & 0.084 & $0 \cdot 056$ & 1.50 & $0 \cdot 14$ & 0.255 \\
\hline \multicolumn{6}{|l|}{ Canadian tiger swallowtail } \\
\hline chokecherry density & 0.723 & 0.435 & 1.67 & 0.09 & $0 \cdot 262$ \\
\hline willow density & 0.554 & 0.438 & 1.27 & $0 \cdot 21$ & $0 \cdot 194$ \\
\hline aspen density & $-0 \cdot 147$ & $0 \cdot 367$ & -0.40 & $0 \cdot 69$ & -0.061 \\
\hline shrub habitat & 0.004 & 0.001 & 0.55 & 0.59 & 0.084 \\
\hline grass habitat & 0.683 & $0 \cdot 507$ & 1.35 & $0 \cdot 18$ & $0 \cdot 214$ \\
\hline \multicolumn{6}{|l|}{ Covariance } \\
\hline ungulates - chokecherry browse & $0 \cdot 425$ & $0 \cdot 143$ & $2 \cdot 97$ & $<0 \cdot 01$ & $0 \cdot 343$ \\
\hline ungulates - willow browse & $0 \cdot 098$ & $0 \cdot 180$ & 0.55 & 0.59 & $0 \cdot 069$ \\
\hline ungulates - aspen browse & $0 \cdot 347$ & $0 \cdot 094$ & $3 \cdot 70$ & $<0.01$ & 0.409 \\
\hline ungulates - shrub habitat & 0.530 & 0.759 & $0 \cdot 70$ & 0.49 & 0.088 \\
\hline ungulates - grass habitat & 0.034 & $0 \cdot 010$ & 3.51 & $<0 \cdot 01$ & $0 \cdot 392$ \\
\hline
\end{tabular}

at a number of scales, thereby making decisions based on more than just information at the nesting shrub site (Stauffer \& Best 1980; Knopf \& Sedgewick 1992). In our study, ungulates reduced horizontal shrub cover by browsing, and because horizontal shrub patterns and density surrounding nests are critical to nest site selection by D. petechia (Stauffer \& Best 1980; Knopf \& Sedgewick 1992), overall reduction in shrub cover at the patch scale supersedes any local beneficial effects associated with the modification of individual shrubs that may provide stable nest sites.

As $D$. petechia select shrub habitat in areas with open canopy cover (Hanski, Fenske \& Niemi1996), an inverse relationship between $D$. petechia abundance and canopy was expected (Collins, James \& Rixxer 1982) and supported in our study. Likewise, a positive relationship between amount of shrub habitat and D. petechia abundance was observed similar to that found by Knopf \& Sedgewick (1992). Positive relationships were observed between canopy cover and horizontal cover and horizontal cover and $D$. petechia abundance. If these effects were transitive, one would expect canopy cover to have a positive relationship with $D$. petechia abundance, when in fact, a negative relationship was demonstrated. It is likely that, when holding horizontal cover constant, areas with higher canopy cover would have fewer D. petechia. That is, a range of percentage canopy cover will support $60 \%$ horizontal cover. Based on our SEM, D. petechia will use areas of $60 \%$ horizontal cover with the least amount of canopy cover.

Canopy cover can limit both light and moisture to understorey plants, thereby limiting understorey development. Increasing light intensity to forest floors increases herbaceous understorey cover (Anderson, Loucks \& Swain 1969). A hypothesized inverse relationship between canopy cover and horizontal cover was not, however, supported. In fact, as canopy cover increased, horizontal cover also increased. This may be explained by the fact that one of the most dominant shrubs for many sites was beaked hazelnut which is shade-tolerant. Light intensity in the relatively open $P$. tremuloides forests is sufficient for hazelnut growth and thus high horizontal cover. Although we did not directly measure light intensity among sites, average canopy cover was $47.7 \%$ (range between 5.5 and $85.4 \%$ ) with 8 to $17 \%$ of full sunlight considered necessary for understorey plant growth (Swain 1964; Anderson, Loucks \& Swain 1969). Light therefore may not be a limiting understorey shrub development in our study sites.

\section{THE PAPILIO CANADENSIS CASCADE}

Browse impact on $P$. virginiana was negatively related to $P$. canadensis abundance by reduction in $P$. virginiana density. Herbivory can alter forage quality by increasing nitrogen and carbon content, chemicals that can enhance growth rates of $P$. canadensis (Scriber 1991), thereby increasing caterpillar growth and survival rates. Browsing may, however, reduce the amount of foliage available to leaf-eating caterpillars, thus restricting carbon and nitrogen gain and thus caterpillar development (Ouellet, Boutin \& Heard 1994). We did not detect an indirect positive relationship between BI and $P$. canadensis abundance. Reductions in $P$. virginiana foliage are therefore a more likely explanation for reductions in $P$. canadensis abundance. Prunus virginiana is highly palatable to 
ungulates (Holsworth 1960; Best, Bork \& Cool 2003) and was expected to be severely impacted by intense and frequent herbivory.

Browsing intensity and frequency, the type of herbivory and the time of year vegetation are browsed, all influence plant morphology and physiology (Danell, Huss-Danell \& Bergström 1985; Danell, Bergström \& Edenius 1994). Many shrub species respond to moderate defoliation due to herbivory by the development of new shoots and stems (Crawley 1983) which may explain the lack of relationship observed between Salix spp. and P. tremuloides browse and corresponding shrub densities. Furthermore, in response to herbivory, resprouting cottonwood (Populus spp.) and Salix spp. containing high amounts of compounds that deter mammalian herbivores may also suggest limited effects of browsing on specific shrub species (Tahvanainen et al. 1985; Martinsen, Driebe \& Whitham 1998). Salix spp.and P. tremuloides stems are highly resilient to disturbance by vegetative resprouting and can therefore rapidly increase when released from intensive browsing (Baker, Peinetti \& Coughenour 2005). This may explain the insignificant relationships between ungulate density and shrub density of Salix spp. and P. tremuloides.

Beaked hazelnut has a high tolerance to browsing (Best, Bork \& Cool 2003; Hood \& Bayley 2009). Because beaked hazelnut is the dominant understorey shrub at most sites within the study area, it may obscure the negative effects of intense browsing on other shrub species. Blyth et al. (1994) demonstrated that annual winter twig use of beaked hazelnut by ungulates in Elk Island National Park ranged from 40 to $55 \%$, making up a large portion of their winter diet. Because the effects of browsing on shrubs accumulate over multiple years, shrub density measured during a single year in summer, particularly for $P$. tremuloides and Salix spp., may not be reflective of general year-round browsing pressure or from previous years.

The lack of relationship between Salix spp. and $P$. tremuloides density and $P$. canadensis abundance may, therefore, mean that at a small spatial scale, P. tremuloides and Salix spp. host plants are ubiquitous and thus not limiting P. canadensis (Rausher 1979b). It should be noted that $P$. canadensis were measured in their adult stage and because adults forage on a variety of flowering plants, habitat requirements are different from the caterpillar stage. Adults may have flown from their larval habitats to nearby areas containing high density of nectar plants. Future research should estimate adult butterfly flight distances or density estimates of P. canadensis caterpillars. Regardless, areas with a higher abundance of larval food plants would be expected on average to have higher local populations of dependent butterflies as observed in our study.

Alternately, $P$. virginiana may act as a preferred larval host plant for $P$. canadensis that resulted in lower dependence or use of $P$. tremuloides and Salix spp. Host preference hierarchy for most butterfly species in Alberta is still unclear. Our results suggest that $P$. canadensis may depend more on $P$. virginiana during their larval stages than other host plants.

The positive relationship demonstrated between amount of grassland habitat and intensity of ungulate use is primarily due to bison. The hypothesized inverse relationship between shrub habitat and $P$. canadensis abundance was not supported. Swallowtail species lay eggs in sunny open habitats (Rausher 1979b) and vegetation structure and composition surrounding host plants significantly influence a butterfly's ability to locate host plants (Tahvanainen \& Root 1972; Atsatt \& O’Dowd 1976). Butterflies use chemical cues to locate host plants and thus in areas with high plant diversity the diversity of cues could reduce plant apparency. More open areas may therefore provide more successful oviposition on host plants. Other factors that influence butterfly search, such as host plant abundance or competition for oviposition sites (Rausher 1979b), are likely to be more important than amount of shrub habitat in an area occupied by a high diversity of shrub species.

Although we demonstrated that $P$. virginiana density influences $P$. canadensis abundance, the method used to quantify $P$. virginiana abundance is likely at too large of a scale to answer questions about host plant and butterfly larval behaviour. Larvae of most butterfly species move relatively short distances when searching for suitable forage with host plants that provide sufficient foliage often limiting larval movement to the plant on which oviposition occurred (Rausher 1979a).

Studies demonstrating trophic cascades involving ungulate herbivores often focus on a single species even though multiple ungulate species in the system influence vegetation structure and composition (Hebblewhite et al. 2005; Ripple \& Beschta 2006). In our study system, six coexisting ungulate species collectively affect primary producers, although bison and elk were the most abundant of the ungulates. Although often considered grazers, bison and elk do browse woody vegetation to the point of negatively affecting plant communities and biodiversity (Ripple et al. 2001; Hebblewhite et al. 2005; Painter \& Ripple 2012), so it is likely they were the primary mediators of the specieslevel trophic cascade demonstrated here.

\section{Conclusion}

Trophic cascades are most common in systems having low diversity, food web complexity and productivity (Polis \& Strong 1996; Schmitz, Hamback \& Beckerman 2000). High productivity may weaken the interactions between species, thereby limiting cascades. The Beaver Hills ecosystem is considered productive and biologically diverse (Bork, Hudson \& Bailey 1997) relative to other wellknown terrestrial ecosystems in western North America where trophic cascades have been reported (e.g. Yellowstone and Zion National Parks). However, ungulate exclosures established in Elk Island National Park in 1999 
illustrate that even this productive ecosystem dominated by woody vegetatively resprouting species is limited by ungulate browsing. Shrub structure, however, often still persists at low heights (Fig. 2).

We provide evidence of a species-level cascade wherein high ungulate density decreases $D$. petechia abundance likely through nest-site limitations or increased nest predation, and limits butterfly abundance of $P$. canadensis through reduction of larval host plant densities. Our study provides evidence of a trophic cascade, initiated by a combined effect of the loss of top predators and human management of ecosystems geared towards maintaining high ungulate densities.

\section{References}

Alberta Biodiversity Monitoring Institute. (2007) Terrestrial Field Data Collection Protocols. www.abmi.ca.

Anderson, R.C., Loucks, O.L. \& Swain, A.M. (1969) Herbaceous response to canopy cover, light intensity, and throughfall precipitation in coniferous forests. Ecology, 50, 255-263.

Atsatt, P.R. \& O'Dowd, D.J. (1976) Plant defense guilds. Science, 193, 24-29.

Bailey, A.W., Irving, B.D. \& Fitzgerald, R.D. (1990) Regeneration of woody species following burning and grazing in Aspen Parkland. Journal of Range Management, 43, 212-215.

Baker, B.W., Peinetti, H.R. \& Coughenour, M.B. (2005) Resilience of willow stems after release from intense elk browsing. Rangeland Ecology and Management, 58, 575-581.

Berger, J., Stacey, P.B., Bellis, L. \& Johnson, M.P. (2001) A mammalian predator-prey imbalance: grizzly bear and wolf extinction affect avian neotropical migrants. Ecological Applications, 11, 947-960.

Best, J.N., Bork, E.W. \& Cool, N.L. (2003) Initial beaked hazel growth responses following protection from ungulate browsing. Journal of Range Management, 56, 455-460.

Blyth, C.B. \& Hudson, R.J. (1987) A Plan for the Management of Vegetation and Ungulates - Elk Island National Park. Elk Island National Park Report, Edmonton, Edmonton. 343 p.

Blyth, C.B., Cool, N.L., Dickinson, A., Kaye, R., Olson, W.E., Osko, T., Madsen, D.S. \& McDougall, B. (1994) Ecosystem Status and Management Recommendations-Elk Island National Park. Heritage Resource Conservation, Elk Island National Park, AB, Canada. 95 p.

Bork, E.W., Hudson, R.J. \& Bailey, A.W. (1997) Upland plant community classification in Elk Island National Park, Alberta, Canada, using disturbance history and physical site factors. Plant Ecology, 130, 171-190.

Cabeza, M., Arponen, A. \& Van Teeffelen, A. (2008) Top predators: hot or not? A call for systematic assessment of biodiversity surrogates. Journal of Applied Ecology, 45, 976-980.

Canadian Forest Service. (2007) Earth Observation for Sustainable Development of Forests (EOSD) 1:250,000 Land Cover Mapping of Canada [digital data]. Government of Canada, Canadian Forest Service, Northern Forestry Centre and Pacific Forestry Centre. http://cfs.nrcan.gc.ca/ pages/337.

Caro, T., Engilis, A. Jr, Fitzherbert, E. \& Gardner, T. (2004) Preliminary assessment of the flagship species concept at a small scale. Animal Conservation, 7, 63-70.

Carpenter, S.R. \& Kitchell, J.F. (1988) Consumer control of lake productivity. BioScience, 38, 764-769.

Carpenter, S.R., Cole, J.J., Hodgson, J.R., Kitchell, J.F., Pace, M.L., Bade, D., Cottingham, D.L., Essington, T.E., Houser, J.N. \& Schindler, D.E. (2001) Trophic cascades, nutrients, and lake productivity: wholelake experiments. Ecological Monographs, 71, 163-186.

Collins, S.L., James, F.C. \& Rixxer, P.G. (1982) Habitat relationships of wood warblers (Parulidae) in north central Minnesota. Oikos, 39, 50-58.

Côté, S.D., Rooney, T.P., Tremblay, J.-P., Dussault, C. \& Waller, D.M. (2004) Ecological impacts of deer overabundance. Annual Review of Ecology, Evolution, and Systematics, 35, 113-147.

Crawley, M.J. (1983) The Dynamics of Animal-plant Interactions. Blackwell, Oxford.
Danell, K., Bergström, R. \& Edenius, L. (1994) Effects of large mammalian browsers on architecture, biomass, and nutrients of woody plants. Journal of Mammalogy, 75, 833-844.

Danell, K., Huss-Danell, K. \& Bergström, R. (1985) Interactions between browsing moose and two species of birch in Sweden. Ecology, 66, 18671878.

Dublin, H.T., Sinclair, A.R. \& McGlade, J. (1990) Elephants and fire as causes of multiple stable states in the Serengeti-Mara woodlands. Journal of Animal Ecology, 59, 1147-1164.

Estes, J.A. \& Duggins, D.O. (1995) Sea otters and kelp forests in Alaska: generality and variation in a community ecological paradigm. Ecological Monographs, 65, 75-100.

Estes, J.A., Terborgh, J., Brashares, J.S., Power, M.E., Berger, J., Bond, W.J., Carpenter, S.R., Essington, T.E., Holt, R.D., Jackson, J.B.C., Marquis, R.J., Oksanen, L., Oksanen, T., Paine, R.T., Pikitch, E.K., Ripple, W.J., Sandin, S.A., Scheffer, M., Schoener, T.W., Shurin, J.B., Sinclair, A.R.E., Soulé, M.E., Virtanen, R. \& Wardle, D.A. (2011) Trophic downgrading of planet earth. Science, 333, 301-306.

Fagan, W. (1997) Omnivory as a stabilizing feature of natural communities. American Naturalist, 150, 554-567.

Fancy, S.G. \& White, R.G. (1985) Energy expenditures by caribou while cratering in snow. Journal of Wildlife Management, 49, 987-993.

Fortin, D., Beyer, H.L., Boyce, M.S., Smith, D.W., Duchesne, T. \& Mao, J.S. (2005) Wolves influence elk movements: behaviour shapes a trophic cascade in Yellowstone National Park. Ecology, 86, 1320-1330.

Gastreich, K.R. (1999) Trait-mediated indirect effects of a therididspider on an ant-plant mutualism. Ecology, 80, 1066-1070.

Grace, J.B. (2006) Structural Equation Modeling and Natural Systems. Cambridge University Press, Cambridge.

Hanski, I.K., Fenske, T.J. \& Niemi, G.J. (1996) Lack of edge effect in nesting success of breeding birds in managed forest landscapes. The Auk, 113, 578-585.

Hebblewhite, M., White, C.A., Nietvelt, C.G., McKenzie, J.A., Hurd, T.E., Fryxell, J.M., Bayley, S.E. \& Paquet, P.C. (2005) Human activity mediates a trophic cascade caused by wolves. Ecology, 86, 2135-2144.

Holsworth, W.N. (1960) Interactions between moose, elk and buffalo in Elk Island National Park, Alberta. M.S. Thesis, University of British Columbia, Vancouver.

Holt, C.A., Fuller, R.J. \& Doman, P.M. (2011) Breeding and post-breeding responses of woodland birds to modification of habitat structure by deer. Biological conservation, 144, 2151-2162.

Hood, G. \& Bayley, S. (2008) The effects of high ungulate densities on foraging choices by beaver (Castor canadensis) in the mixed-wood boreal forest. Canadian Journal of Zoology, 86, 484-496.

Hood, G. \& Bayley, S. (2009) A comparison of riparian plant community response to herbivory by beavers (Castor canadensis) and ungulates in Canada's boreal mixed-wood forest. Forest Ecology and Management., 258, 1979-1989.

Kauffman, M.J., Brodie, J.F. \& Jules, E.S. (2010) Are wolves saving Yellowstone's aspen? A landscape-level test of a behaviorally mediated trophic cascade. Ecology, 91, 2742-2755.

Kerr, J.T. (1997) Species richness, endemism, and the choice of protected areas for conservation. Conservation Biology, 11, 1094-1100.

Knopf, F.L. \& Sedgewick, J.A. (1992) An experimental study of nest-site selection by yellow warblers. Condor, 94, 734-742.

Layberry, R.A., Hall, P.W. \& Lafontaine, J.D. (1998) The Butterflies of Canada. University of Toronto Press, Toronto.

Lemmon, P.E. (1956) A spherical densiometer for estimating forest overstory density. Forest Science, 2, 314-320.

Marden, J.H. \& Chai, P. (1991) Aerial predation and butterfly design: how palatability, mimicry, and the need for evasive flight constrain mass allocation. American Naturalist, 138, 15-36.

Martinsen, G.D., Driebe, E.M. \& Whitham, T.G. (1998) Indirect interactions mediated by changing plant chemistry: beaver browsing benefits beetles. Ecology, 79, 192-200.

McCann, K.S. (2000) The diversity-stability debate. Nature, 405, 228-233.

McLaren, B.E. \& Peterson, R.O. (1994) Wolves, moose, and tree rings on Isle Royale. Science, 266, 1555-1558.

Olechnowski, B.F. \& Debinski, D.M. (2008) Response of songbirds to riparian willow habitat structure in the Greater Yellowstone ecosystem. Wilson Journal of Ornithology, 120, 830-839.

Ouellet, J.P., Boutin, S. \& Heard, D.C. (1994) Responses to simulated grazing and browsing of vegetation available in the arctic. Canadian Journal of Zoology, 72, 1426-1435. 
Ozaki, K., Isono, M., Kawahara, T., Ida, S., Kudo, T. \& Fukuyama, K. (2006) A mechanistic approach to evaluation of umbrella species as conservation surrogates. Conservation Biology, 20, 1507-1515.

Pace, M.L., Cole, J.J., Carpenter, S.R. \& Kitchell, J.F. (1999) Trophic cascades revealed in diverse ecosystems. Trends in Ecology \& Evolution, 14, 483-488.

Paine, R.T. (1966) Food web complexity and species diversity. American Naturalist, 100, 65-75.

Painter, L.E. \& Ripple, W.J. (2012) Effects of bison on willow and cottonwood in northern Yellowstone National Park. Forest Ecology and Management, 264, 150-158.

Parker, K.L., Robbins, C.T. \& Hanley, T.A. (1984) Energy expenditures for locomotion by mule deer and elk. Journal of Wildlife Management, 48, 474-488.

Persson, L. (2005) Trophic Cascades. Encyclopedia of Life Sciences. John Wiley \& Sons, Ltd. DOI: 10.1038/npg.els.0003183 www.els.net.

Polis, G.A. (1999) Why are parts of the worldgreen? Multiple factors control productivity and the distribution of biomass. Oikos, 86, 3-15.

Polis, G.A. \& Holt, R.D. (1992) Intraguild predation: the dynamics of complex trophic interactions. Trends in Ecologly \& Evolution, 7, 151-154.

Polis, G.A. \& Strong, D.R. (1996) Food web complexity and community dynamics. American Naturalist, 147, 813-846.

Pollard, E. \& Yates, T.J. (1993) Monitoring Butterflies for Ecology and Conservation. Joint Nature Conservation Committee Monks Wood London, UK.

Power, M.E. (1990) Effects of fish in river food webs. Science, 250, 811814.

Prins, H.H.T. \& Van der Jeugd, H.P. (1993) Herbivore population crashes and woodland structure in east Africa. Journal of Ecology, 81, 305-314.

Rausher, M.D. (1979a) Egg recognition: its advantage to a butterfly. Animal Behaviour, 27, 1034-1040.

Rausher, M.D. (1979b) Larval habitat suitability and oviposition preference in three related butterflies. Ecology, 60, 503-511.

Ripple, W.J. \& Beschta, R.L. (2006) Linking a cougar decline, trophic cascade, and catastrophic regime shift in Zion National Park. Biological Conservation, 33, 397-408.

Ripple, W.J. \& Beschta, R.L. (2012) Trophic cascades in Yellowstone: the first 15 years after wolf reintroduction. Biological Conservation, 145, 205-213.

Ripple, W.J. \& Larsen, E. (2000) Historic aspen recruitment, elk, and wolves in northern Yellowstone National Park, USA. Biological Conservation, 95, 361-370.

Ripple, W.J., Larsen, E.J., Renkin, R.A. \& Smith, D.W. (2001) Trophic cascades among wolves, elk and aspen on Yellowstone National Park's northern range. Biological Conservation, 102, 227-234.

Robel, R.J., Briggs, J.N., Dayton, A.D. \& Hulbert, L.C. (1970) Relationships between visual obstruction measurementsand weight of grassland vegetation. Journal of Range Management, 23, 295-297.

Royer, R.A., Austen, J.E. \& Newton, W.E. (1998) Checklist and 'Pollard walk' butterfly survey methods on public lands. American Midland Naturalist, 140, 358-371.

Schmitz, O.J., Hamback, P.A. \& Beckerman, A.P. (2000) Trophic cascades in terrestrial systems: a review of the effects of carnivore removals on plants. American Naturalist, 155, 141-153.

Scriber, J.M. (1991) Differential suitability of 12 Great Lakes tree species for Papilio canadensis (Lepidoptera: Papilionidae) larval survival and growth. Great Lakes Entomology, 24, 239-252.
Sergio, F., Newton, I., Marchesi, L. \& Pedrini, P. (2006) Ecologically justified charisma: preservation of top predators delivers biodiversity conservation. Journal of Applied Ecology, 43, 1049-1055.

Sergio, F., Caro, T., Brown, D., Clucas, B., Hunter, J., Ketchum, J., McHugh, K. \& Hiraldo, F. (2008) Top predators as conservation tools: ecological rationale, assumptions, and efficacy. Annual Review of Ecology, Evolution \& Systematics, 39, 1-19.

Singer, F.J. \& Renkin, R.A. (1995) Effects of browsing by native ungulates on the shrubs in big sagebrush communities in Yellowstone National Park. Great Basin Naturalist, 55, 201-212.

Skalski, J.R., Ryding, K.E. \& Millspaugh, J.J. (2005) Wildlife Demography: Analysis of Sex, Age, and Count Data. Elsevier Academic Press, Burlington, MA.

Stauffer, D. \& Best, L.B. (1980) Habitat selection by birds of riparian communities: evaluating effects of habitat alterations. Journal of Wildlife Management, 44, 1-15.

Strong, D.R. (1992) Are all trophic cascades wet? Differentiation and donor control in speciose ecosystems. Ecology, 73, 747-754.

Sullivan, T.P. \& Sullivan, D.S. (1982) Population dynamics and regulation of the Douglas squirrel (Tamiasciurus douglasii) with supplemental food Oecologia, 53, 264-270.

Swain, A.M. (1964) Relationship of understory plants to age and density of conifer forest. M.Sc. Thesis, University of Wisconsin, Madison.

Tahvanainen, J.O. \& Root, R.B. (1972) The influence of vegetational diversity on the population ecology of a specialized herbivore, Phyllotretacruciferae (Coleoptera: Chrysomelidae). Oecologia, 10, 321-346.

Tahvanainen, J., Helle, E., Julkunen-Tiitto, R. \& Lavola, A. (1985) Phenolic compounds of willow bark as deterrents against feeding by mountain hare. Oecologia, 65, 319-323.

Terborgh, J., Lopez, L., Nunez, P., Rao, M., Shahabuddin, G., Orihuela, G., Riveros, M., Ascanio, R., Adler, G.H., Lambert, T.D. \& Balbas, L. (2001) Ecological meltdown in predator-free forest fragments. Science, 294, 1924-1925.

Thompson, F.R. (2007) Factors affecting nest predation on forest songbirds in North America. Ibis, 149, 98-109.

Trussell, G.C., Ewanchuk, P.J. \& Bertness, M.D. (2002) Field evidence for trait-mediated indirect interactions in a rocky intertidal food web. Ecology Letters, 5, 241-245.

White, C.A., Olmsted, C.E. \& Kay, C.E. (1998) Aspen, elk, and fire in the Rocky Mountain national parks of North America. Wildlife Society Bulletin, 26, 449-462.

Received 20 November 2012; accepted 6 April 2013

Handling Editor: Tim Coulson

\section{Supporting Information}

Additional Supporting Information may be found in the online version of this article.

Appendix S1. Results of literature review on defecation rates of Alces alces (moose), Odocoileus spp. (deer), Cervus elaphus (elk) and Bison bison (bison). 